\title{
Abundance and dynamics of anopheline larvae in a highland malarious area of south-central Ethiopia
}

\author{
Abebe Animut ${ }^{1,2^{*}}$, Teshome Gebre-Michael ${ }^{2}$, Meshesha Balkew ${ }^{2}$ and Bernt Lindtjørn ${ }^{1}$
}

\begin{abstract}
Background: Malaria is a public health problem in Ethiopia, and increasingly so in highland areas, possibly because of global warming. This study describes the distribution, breeding habitat and monthly dynamics of anopheline larvae in Butajira, a highland area in south-central Ethiopia.

Methods: A study of the abundance and dynamics of Anopheles larvae was undertaken at different sites and altitudes in Butajira from July 2008 to June 2010. The sites included Hobe (1817 m.a.s.l), Dirama (1995m.a.s.l.) and Wurib (2196m.a.s.l.). Potential anopheline larval habitats were surveyed once per month in each village. The recorded characteristics of the habitats included habitat type, $\mathrm{pH}$, surface debris, emergent plants, algae, substrate, turbidity, temperature, length, width, depth, distance to the nearest house and anophelines. The Spearman correlation coefficient and Mann-Whitney $U$ test were used to calculate the degree of association between the density of anopheline species and key environmental factors.

Results: Among the different types of habitat surveyed, the Odamo, Akamuja and Assas streams and Beko swamp were positive for anopheline larvae. A total of 3,957 third and fourth instar larvae were collected from the three localities, and they represented ten species of anophelines. These were: Anopheles cinereus (32.5\%), An. arabiensis (31.4\%), An. chrysti (23\%), An. demeilloni (12.2\%), An. pretoriensis (0.6\%), An. azaniae (0.1\%), An. rufipes(0.1\%), An. sergentii (0.06\%), An. garnhami (0.06\%) and An. pharoensis (0.03\%). The density of anopheline larvae was highest during the dry months. An. arabiensis was widely distributed, and its density decreased from the lowest elevation in Hobe to the highest in Wurib. The density of An. arabiensis larvae was correlated positively with larval habitat temperature $(r=0.33, p<0.05)$ and negatively with depth of larval habitat $(r=-0.56, p<0.05)$.

Conclusion: Ten species of anophelines were identified, including two known vectors of malaria (An. arabiensis and An. pharoensis), along streams in Butajira. Larvae of An. arabiensis were found in streams at 2200m.a.s.l. This possible expansion of the malaria vector to highland areas indicates an increasing risk of malaria because a large proportion of the Ethiopian population live above this altitude.
\end{abstract}

\section{Background}

Malaria is the leading cause of mortality and morbidity in Ethiopia in areas up to 2500 metres above sea level (m.a.s.l) [1], although cases have been reported up to 3000 m.a.s.l. in some areas [2]. About $70 \%$ of the population is estimated to be at risk of infection every year [3]. Transmission of the disease is unstable in many highland

\footnotetext{
* Correspondence: animut2004@yahoo.com

${ }^{1}$ Center for International Health, University of Bergen, Bergen, Norway ${ }^{2}$ Aklilu Lemma Institute of Pathobiology, Addis Ababa University, Addis Ababa, Ethiopia
}

(C) 2012 Animut et al.; licensee BioMed Central Ltd. This is an Open Access article distributed under the terms of the Creative Commons Attribution License (http://creativecommons.org/licenses/by/2.0), which permits unrestricted use, distribution, and reproduction in any medium, provided the original work is properly cited.

areas of the country, where the population has low immunity, and these regions experience malaria epidemics [4]. Anopheles arabiensis, a member of the An. gambiae complex, is the main vector of malaria in the country [5], while An. pharoensis, An. funestus and An. nili represent secondary vectors $[6,7]$.

The transmission of malaria in high altitude areas of Ethiopia $[1,2,8]$ might possibly be due to global warming [9], land use practices [10,11] and ecological changes $[12,13]$ that could favour the breeding and survival of vectors. Warmer weather and increased water temperature 
enhance malaria transmission in the highlands by shortening the development time from eggs to adult mosquitoes [14], increasing the number of human blood meals taken by adults, increasing the frequency of egg laying and increasing the survival rate of adult mosquitoes $[14,15]$. Increased warmth also shortens the sporogonic cycle of the parasite in the vector, which results in increased intensity of malaria transmission [16,17]. The continuation of global climate change could therefore allow malaria to expand into the highlands of east Africa [18], threatening the lives of millions of people.

The existing malaria intervention strategy, which includes indoor residual insecticide spraying, nets treated with long-lasting insecticide, and case management, has been reducing the impact of the disease in Ethiopia. Nevertheless, spread of insecticide-resistant vectors $[19,20]$ and drug-resistant malaria parasites $[21,22]$ may result in disease outbreaks. Therefore, control of larvae, which has so far been given little attention, should be reintroduced and implemented together with the existing strategy. Larval control will result in the reduction of the adult mosquito population, subsequently limiting malaria transmission [23]. However, current knowledge of the distribution and dynamics of the aquatic stages of mosquitoes is not adequate. Anopheles mosquitoes breed at the edges of rivers and streams, in temporary rain pools, ponds, dams, drainage ditches, burrow pits, rice fields, swamp margins, roadside puddles and in tree holes close to human dwellings [23-25]. However, mosquitoes differ in their preference for the type, size, turbidity, algal cover and stability of the habitat [26-28]; these factors determine the density, size and disease transmission competence of vectors [25,29]. Although malaria has become an important health problem in the south-central highland area of Butajira [30,31], information on the dynamics of the immature stages of the vectors is scarce. The aim of this study was to describe the species distribution and seasonal dynamics of anopheline larvae in the south-central highland area of Butajira. Such information is important in order to implement effective interventions and establish an early warning system for the disease in this country.

\section{Methods}

\section{Study area}

The study was undertaken in the Butajira area in the south-central highlands of the Southern Nations and Nationalities Regional State of Ethiopia, which is located $135 \mathrm{~km}$ south of Addis Ababa (Figure 1).

For larval sampling, three study sites were selected. These included Hobe (1817 metres above sea level), Dirama (1995m.a.s.l.) and Wurib (2196 m.a.s.l.). The sites are villages close to the Odamo, Akamuja and Assas streams, respectively. They were selected by Health Extension
Workers on the basis of habitat availability, accessibility and malaria case reports. Rainfall data for the area (July 2008 to March 2010) was obtained from the National Meteorological Agency of Ethiopia from the only station in Butajira town, which is located 5-20 km from the study areas. On the basis of the previous thirty years of meteorological data from the area (National Meteorological Agency of Ethiopia), the average monthly rainfall is $94.6 \mathrm{~mm}$ and the relative humidity is $60.8 \%$, while the average maximum and minimum temperatures are $25.5^{\circ} \mathrm{C}$ and $11.5^{\circ} \mathrm{C}$, respectively. Peak rainfall occurs between July and August, while the lowest level occurs in November and December, with little rain between March and May.

\section{Larval sampling and processing}

Sampling for anopheline larvae was undertaken once a month from July 2008 to June 2010. Streams, water wells, small rain pools, pools in hoof- or foot-prints and false banana (Ensete ventricular) leaf axils were surveyed for the presence of larvae, and collections were made by applying a standard sampling procedure [27,32-34]. Three to ten samples were taken with a soup ladle ( $350 \mathrm{ml}$ capacity) from each breeding habitat, depending on the size of the habitat and the availability of larvae. In streams, dipping was performed at the edges and stream beds for a distance of 600 to $1600 \mathrm{~m}$, depending on presence of larvae. Along the streams the average distance between two consecutive larval sampling points was $100 \mathrm{~m}$.

Larvae were sorted into culicines and anophelines. All anopheline larvae sampled from each sampling point were identified as $1^{\text {st }}, 2^{\text {nd }}, 3^{\text {rd }}$ or $4^{\text {th }}$ larval instars, and the corresponding counts were recorded after transferring the larvae from the sampling dipper to white enamel trays. All culicine larvae and the $1^{\text {st }}$ and $2^{\text {nd }}$ anopheline larval instars were discarded. All late anopheline instars $\left(3^{\text {rd }}\right.$ and $4^{\text {th }}$ ) were preserved in $70 \%$ alcohol after being killed in hot water $\left(\mathrm{ca} .60^{\circ} \mathrm{C}\right)$ [35]. In the laboratory, the larvae were mounted in gum-chloral mountant on slides and the species identified on the basis of morphology under a microscope [36]. Furthermore, about $10 \%$ of the larval species identified morphologically by the first author (AA) were selected randomly and subjected to reidentification and confirmation by one of the senior and more experienced co-authors (MB). Larvae that were members of the $A n$. gambiae complex were inferred from the results of speciesspecific PCR conducted on the adults collected from the same study sites (manuscript under preparation). After identification of the late instars, the density of the most common species was expressed as the number of larvae per 100 dips.

\section{Characterization of larval habitat}

The types of larval habitats and their characteristics, such as speed, length, width, depth, $\mathrm{pH}$, turbidity, trees 


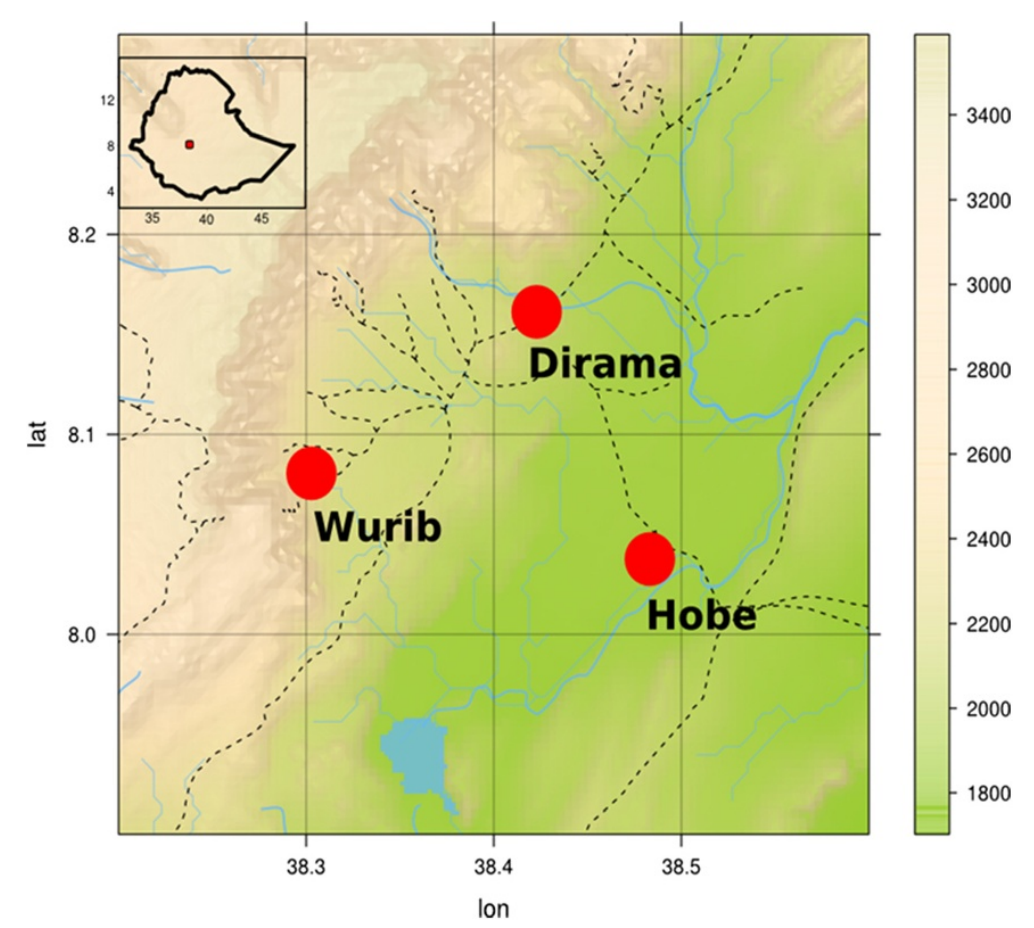

Figure 1 Location of the Butajira study area in the south-central Ethiopian Highlands.

nearby (shade), distance to the nearest inhabited house, availability of emergent plants and substrate types were described by technicians and the first author (AA). The flow speed of aquatic habitat was described visually as fast flowing, slowly flowing or stagnant (not flowing). Habitat length, width, depth and distance to the nearest house was measured using measuring tape; shade was recorded as present or absent by observing terrestrial vegetation and/or trees and their branches near the breeding habitat. Emergent plants included both aquatic and immersed terrestrial vegetation [27]. Turbidity was measured by placing a water sample in a clean glass test tube and holding it against a white background; it was classified into four levels: clear, low, medium and high [27]. Substrate type was classified as muddy or sandy. The $\mathrm{pH}$ of the water was measured using a portable $\mathrm{pH}$ meter, and the water temperature was measured using a minitherm HI 8753 (Romania) digital thermometer.

\section{Statistical analysis}

The data were entered and analysed using SPSS version 16.0 statistical software (SPSS Inc., Chicago, IL). Monthly dynamics of the density of the major anopheline species and the corresponding monthly rainfall data are presented in line charts. The association of the density of the major species with habitat characteristics such as temperature, depth and $\mathrm{pH}$ was analysed using the Spearman correlation coefficient, while associations with substrate type (muddy or sandy), turbidity (low or medium), surface debris (present or absent), and surface algae (present or absent) were analysed using the Mann-Whitney $U$ test. The extended Mantel-Haenszel chi-square test for linear trend was used to investigate the trends in major anopheline density at the Hope, Dirama and Wurib sites. The Kappa value was calculated to study the agreement between the researchers in the identification of larval species.

\section{Results}

Potential anopheline breeding habitats surveyed from July 2008 to June 2010 in Hobe, Dirama and Wurib villages are presented in Table 1. Among the different types of habitat surveyed, three streams (Odamo, Akamuja and Assas) and one swamp (Beko) were found to harbour anopheline larvae. No anopheline larvae were found in water wells, false banana axils, hoof-prints and most temporary rain pools.

During the study period, 9532 immature anopheline larvae were collected, of which $3171(33.3 \%)$ were $1^{\text {st }}$ instars, $2414(25.3 \%)$ were $2^{\text {nd }}$ instars, 2266 (23.8\%) were $3^{\text {rd }}$ instars and $1681(17.6 \%)$ were $4^{\text {th }}$ instars. Among the total sampled, 2302 were from Odamo stream, 37 from a rain pool in Hobe, 1961 from Assas stream, 2294 from Beko swamp, 2925 from Akamuja Stream and 13 from a foot-print in Dirama village.

Of 3947 late $\left(3^{\text {rd }}\right.$ and $\left.4^{\text {th }}\right)$ instar Anopheles larvae, 3100 (78.5\%) were identified to species level (Table 2). The 
Table 1 Aquatic habitats surveyed and anopheline larvae collections in Hobe, Dirama and Wurib Kebeles of Butajira area, south-central Ethiopia (July 2008 to June 2010)

\begin{tabular}{|c|c|c|c|c|c|c|c|}
\hline \multirow[t]{2}{*}{ Kebele } & \multirow{2}{*}{$\begin{array}{l}\text { Study } \\
\text { site }\end{array}$} & \multirow[t]{2}{*}{ Habitat Type (n) } & \multicolumn{5}{|c|}{ Anopheline larvae stages (n) } \\
\hline & & & $1^{\text {st }}$ & $2^{\text {nd }}$ & $3^{\text {rd }}$ & $4^{\text {th }}$ & Total \\
\hline \multirow[t]{4}{*}{ Hobe } & Hobe & Odamo stream(1) & 673 & 671 & 691 & 267 & 2302 \\
\hline & & Wells (5) & 0 & 0 & 0 & 0 & 0 \\
\hline & & Rain pools (11) & 25 & 12 & 0 & 0 & 37 \\
\hline & & Hoof/Foot prints (20) & 0 & 0 & 0 & 0 & 0 \\
\hline \multirow[t]{4}{*}{ Dirama } & Dirama & Akamuja stream (1) & 942 & 741 & 739 & 503 & 2925 \\
\hline & & Rain pools (3) & 13 & 0 & 0 & 0 & 13 \\
\hline & & Hoof/Foot prints (10) & 0 & 0 & 0 & 0 & 0 \\
\hline & & False banana axils (2) & 0 & 0 & 0 & 0 & 0 \\
\hline \multirow[t]{11}{*}{ Wurib } & Meter & Assas stream (1) & 613 & 432 & 390 & 526 & 1961 \\
\hline & & Wells (2) & 0 & 0 & 0 & 0 & 0 \\
\hline & & Rain pools (4) & 0 & 0 & 0 & 0 & 0 \\
\hline & & Hoof/Foot prints (9) & 0 & 0 & 0 & 0 & 0 \\
\hline & & false banana axils (8) & 0 & 0 & 0 & 0 & 0 \\
\hline & Beko & Beko Swamp (1) & 905 & 558 & 446 & 385 & 2294 \\
\hline & & Wells (2) & 0 & 0 & 0 & 0 & 0 \\
\hline & & Rain pools (2) & 0 & 0 & 0 & 0 & 0 \\
\hline & & Hoof/Foot prints (3) & 0 & 0 & 0 & 0 & 0 \\
\hline & & false banana axils (2) & 0 & 0 & 0 & 0 & 0 \\
\hline & & Total & 3171 & 2414 & 2266 & 1681 & 9532 \\
\hline
\end{tabular}

Numbers in parentheses represent habitats surveyed.

remaining 847 (21.5\%) were either lost or could not be identified because of damage to larval parts during processing, or were not mounted on slides for identification. Ten percent $(n=305)$ of the morphologically identified larvae were selected randomly and subjected to re-identification by a second researcher. There was very good agreement (Kappa $=0.89, p<0.01$ ) between the researchers in the morphological identification of the anopheline larvae to species level. Anopheles cinereus was the dominant species (32.5\%), followed by An. gambiae s.l. (= An. arabiensis in the present work) (31.4\%), An. chrysti (23\%) and An. demeilloni (12.2\%).

Larvae of $A n$. arabiensis were found in the four main breeding sites, with the highest density in Hobe (lowest elevation area) and the lowest density in Wurib (highest elevation area). Larval density declined significantly from

Table 2 Species and distribution of anopheline larvae along the four breeding habitats of Butajira area, south-central Ethiopia (July 2008 -June 2010)

\begin{tabular}{|c|c|c|c|c|c|}
\hline \multirow{2}{*}{$\begin{array}{l}\text { Immature } \\
\text { anopheline species }\end{array}$} & \multicolumn{5}{|c|}{ Breeding habitats } \\
\hline & Odamo Stream & Akamuja stream & Assas stream & Beko wamp & Total (\%) \\
\hline Anopheles cinereus & 10 & 576 & 235 & 187 & $1008(32.52)$ \\
\hline Anopheles arabiensis & 684 & 267 & 3 & 19 & $973(31.39)$ \\
\hline Anopheles chrysti & 13 & 118 & 110 & 471 & $712(22.97)$ \\
\hline Anopheles demeilloni & 10 & 46 & 186 & 136 & $378(12.19)$ \\
\hline Anopheles pretoriensis & 0 & 0 & 0 & 17 & $17(0.55)$ \\
\hline Anopheles azaniae & 0 & 1 & 0 & 3 & $4(0.13)$ \\
\hline Anopheles rufipes & 0 & 0 & 0 & 3 & $3(0.10)$ \\
\hline Anopheles sergentii & 0 & 0 & 0 & 2 & $2(0.06)$ \\
\hline Anopheles garnhami & 0 & 1 & 0 & 1 & $2(0.06)$ \\
\hline Anopheles pharoensis & 0 & 1 & 0 & 0 & $1(0.03)$ \\
\hline Total & 717 & 1010 & 534 & 839 & $3100(100)$ \\
\hline
\end{tabular}


the lowland to the highland areas (chi-square for linear trend $=1794, p<0.01)$. On the other hand, the density of An. cinereus, An. chrysti and An. demeilloni increased from Hobe to Wurib. The six other species, An. pretoriensis, An. rufipes, An. sergentii, An. azaniae, An. garnhami and $A n$. Pharoensis, were rare; the first five were sampled from the high altitude village while the last species was obtained from the intermediate altitude.

Figure 2 shows the seasonal density of the four common Anopheles species, expressed as the number of larvae per 100 ladle dips, and the corresponding monthly rainfall of the area. An. arabiensis larvae were predominant in Hobe, with high density from December 2008 to April 2009. This was the dry season, when the monthly rainfall was below $40 \mathrm{~mm}$. The density of Anopheles larvae was generally lowest during July and August, corresponding to the highest amount of monthly rainfall. The density of $A n$. demeilloni, An. chrysti and An. cinereus larvae showed similar trends. Among the three villages, Wurib had diverse species of anopheline larvae.

Beko swamp showed the presence of anopheline larvae most frequently (during 16 surveys), followed by Akamuja stream (11 surveys), among the 24 larval surveys (Table 3 ). The highest average water temperature was recorded along Odamo stream $\left(26^{\circ} \mathrm{C}\right)$ and the lowest along Assas stream and in Beko Swamp $\left(23^{\circ} \mathrm{C}\right)$. On average, a $1600 \mathrm{~m}$ stretch of the Akamuja stream was surveyed once each month for the presence of anophelines, and the shortest habitat distance surveyed, $600 \mathrm{~m}$, was along the Beko swamp. Beko was the deepest permanent breeding habitat
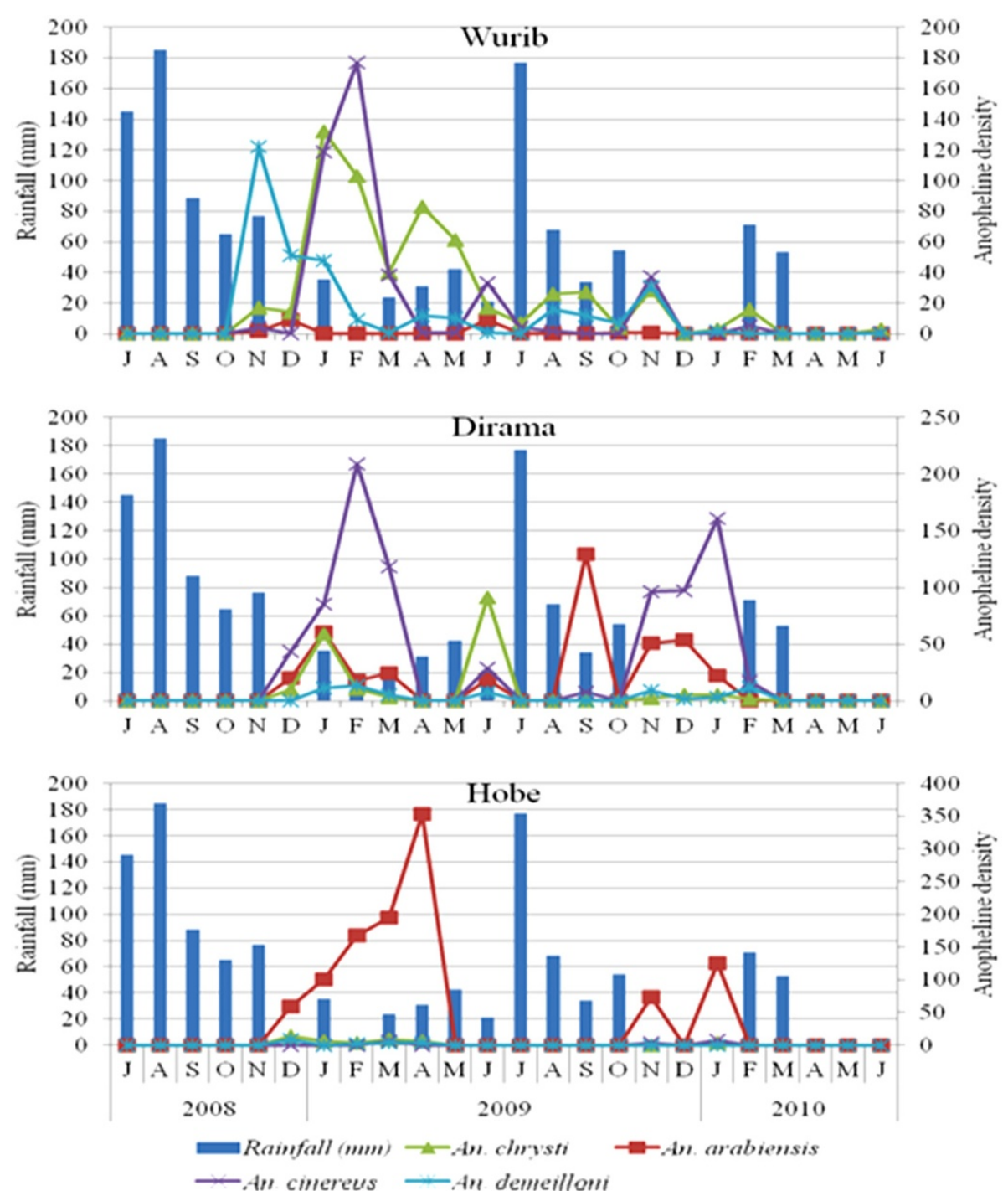

Figure 2 Monthly rainfall and Anopheles larva density in Hobe, Dirama and Wurib villages of Butajira area, south-central Ethiopia, July 2008- June 2010. 
Table 3 Characteristics of streams during anopheline larvae occurrence, south-central Ethiopia, July 2008-June 2010

\begin{tabular}{llllllll}
\hline $\begin{array}{l}\text { Local name } \\
\text { of Stream }\end{array}$ & $\begin{array}{l}\text { Frequency of } \\
\text { occurrence }\end{array}$ & \multicolumn{5}{c}{ Habitat characteristic $(\mathbf{M} \pm \mathbf{S D})$} \\
\cline { 3 - 8 } & & Temperature $\left({ }^{\mathbf{0}} \mathbf{C}\right)$ & $\mathbf{p H}$ & Length $(\mathbf{m})$ & Width $(\mathbf{m})$ & Depth $(\mathbf{c m})$ & Nearest domicile $(\mathbf{m})$ \\
\hline Odamo & 7 & $26.1 \pm 2.5$ & $7.2 \pm 0.3$ & $1597 \pm 7.6$ & $4.3 \pm 0.5$ & $3.4 \pm 0.5$ & 350 \\
Akamuja & 11 & $24.5 \pm 1.8$ & $7.5 \pm 0.7$ & 1600 & $5.4 \pm 0.5$ & $4.4 \pm 0.8$ & 200 \\
Assas & 6 & $22.7 \pm 4.1$ & $7.1 \pm 0.1$ & $1033 \pm 81.7$ & $3.2 \pm 0.3$ & $5.0 \pm 0.6$ & $120 \pm 42.2$ \\
Beko Swamp & 16 & $23.0 \pm 2.3$ & $7.2 \pm 0.3$ & 600 & $4.4 \pm 0.5$ & $5.3 \pm 1.5$ & 20 \\
\hline
\end{tabular}

$\mathrm{M} \pm \mathrm{SD}=$ mean \pm standard deviation.

$(5.3 \pm 1.5 \mathrm{~cm})$ and had the closest human inhabitants (20 m).

The density of An. arabiensis late instars increased significantly with increasing habitat temperature $(r=0.33$, $p<0.01$ ) and also with decreasing depth of habitat $(\mathrm{r}=-0.56, p<0.05)$ (Table 4). Analysis using the MannWhitney $U$ test revealed significantly higher larval density in sandy habitats $(\mathrm{z}=-3.648, p<0.01)$ when compared with habitats with muddy substrate. The density of An. demeilloni was negatively associated with habitat temperature $(\mathrm{r}=-0.387, p<0.05)$. An. arabiensis, An. chrysti, An. cinereus and $A n$. demeilloni were not significantly associated with habitat characteristics such as $\mathrm{pH}$, turbidity, surface debris and surface algae in any of the streams. These habitats supported larval development at their shallow edges, where the speed of flow was low, and on their beds in small and stagnant pools. No emergent vegetation was available along the three streams, but was present in Beko swamp. There was no canopy cover along the anopheline-positive habitats, except for some scattered trees, with no measurable shade on the breeding habitats. All the land close to the breeding habitats was cultivated by farmers.

\section{Discussion}

Ten anopheline species were identified in Butajira. The predominant species was An. Arabiensis, which is the main vector of malaria in the country $[5,6]$. Its density decreased from Hobe at the lowest elevation (about 1800 m.a.s.l.) to Wurib at 2200 m.a.s.l. Two of these species (An. gambiae s.l, presumably $A n$. arabiensis and $A n$. chrysti) have been reported from neighbouring villages at about the same altitude [37]. This shows that malaria transmission in the area [30,31] decreases with increasing altitude. Malaria-related mortality in the area was reported previously to follow a similar altitudinal trend [31].

Table 4 Association between habitat characteristics and anopheline larval density, south-central Ethiopia, July 2008 to June 2010

\begin{tabular}{|c|c|c|c|c|}
\hline & Species & & & \\
\hline Habitat characteristics & An. arabiensis & An. chrysti & An. cinereus & An. demeilloni \\
\hline \multicolumn{5}{|l|}{ Correlation } \\
\hline $\mathrm{pH}$ & -0.2 & 0.0 & 0.1 & -0.2 \\
\hline Temperature $\left({ }^{0} \mathrm{C}\right)$ & $0.3^{*}$ & -0.1 & 0.2 & $-0.3^{*}$ \\
\hline Depth $(\mathrm{cm})$ & $-0.6^{* *}$ & 0.2 & 0.0 & 0.2 \\
\hline \multicolumn{5}{|c|}{ Differences of means (medians) } \\
\hline \multicolumn{5}{|l|}{ Substrate } \\
\hline Muddy & $1.9(0.0)^{* *}$ & $52.5(25.8)^{*}$ & $19.2(2.3)$ & $15.8(14.3)$ \\
\hline Sandy & $61.5(23.3)$ & $17.7(4.1)$ & $54.1(12.5)$ & $16.7(4.2)$ \\
\hline \multicolumn{5}{|l|}{ Turbidity } \\
\hline Low & $39.5(2.5)$ & $31.1(7.7)$ & $42.2(7.5)$ & $15.9(5.0)$ \\
\hline Medium & $1.1(1.1)$ & $40.9(40.9)$ & 0.0 & $23.9(24.0)$ \\
\hline \multicolumn{5}{|l|}{ Surface debris } \\
\hline Present & $38.0(2.2)$ & $32.4(8.7)$ & $42.2(7.5)$ & $15.0(5.1)$ \\
\hline Absent & $30.3(30.3)$ & $17.7(17.7)$ & 0.0 & $42.1(42.1)$ \\
\hline \multicolumn{5}{|l|}{ Surface Algae } \\
\hline Present & $38.6(2.2)$ & $32.2(8.9)$ & $41.1(7.4)$ & $16.7(7.6)$ \\
\hline Absent & 0.0 & $8.6(8.6)$ & $2.9(2.9)$ & 0.0 \\
\hline
\end{tabular}


We found that $A n$. arabiensis breeds at 2196 m.a.s.l., which is above the altitude reported previously from Kenyan highlands [38,39]. This suggests that malaria vectors are breeding in highland areas, and global warming [9] could be one explanation for the expansion of $A n$. arabiensis and An. pharoensis in the Butajira highlands. The 1958 malaria epidemic that affected most highland areas, including at 2600 m.a.s.l. [8], and a recent report of malaria prevalence of $3.2 \%$ at an altitudinal range of 2500 to 3000 m.a.s.l. [2] could be attributed partly to the expansion of the vectors into areas of higher elevation. Expansion of these vectors to highland areas is a serious threat because most of the Ethiopian population lives in the highlands.

The study revealed that the edges and beds of streams serve as anopheline breeding habitats in the Butajira area during months with low precipitation, as reported previously in the central Rift Valley of Ethiopia [40] and Western Kenya [41]. Streambed pools were also productive breeding habitats of An. arabiensis during low rainfall seasons in Eritrea [42]. Similar findings have also been documented in other areas of East Africa [32,42]. Streams can produce large vector populations during dry seasons, and hence larval management that targets streambed pools and stream edges may bring substantial reduction in vector density, and subsequently the incidence of malaria $[23,43]$, in the south-central highlands of Ethiopia. The absence of larvae along the streams during the rainy months could result from increased stream flow, which carries away immature stages of mosquitoes from their breeding points. Heavy rainfall could also kill larvae directly [44].

Larvae could not be investigated in temporary water collections formed during rain, in water wells, or in Ensete leaf axils. The absence of larvae from most of the temporary collections of surface water could be due to rapid infiltration of the rain water into the soil and high evaporation. Many permanent water wells did not support anopheline larvae, except culicines. This could be due to their depth, which ranges from 15 to $20 \mathrm{~m}$ from the surface, and their water volume, which prevents the entry of direct sunlight and could in turn lower habitat temperature and reduce the availability of the food necessary for larval development. Although temporary habitats may dry out or be flushed out before immature anophelines complete their development [28], they are unpredictable in occurrence and may make a small contribution to overall adult productivity [43]. In addition, their contribution to vector breeding should not be ignored [13] because some may support anopheline breeding. Given that we were not able to perform weekly or daily sampling of larvae, we might have missed some potential and temporary breeding habitats between the monthly surveys, and this could have biased our results.
We recommend that future studies should be carried out at frequent intervals to produce more detailed information on the dynamics of anopheline larvae.

The anopheline breeding points were shallow edges and beds of streams that were sunlit, slow flowing or stagnant, with or without debris and surface algae. Similar habitat types were reported from the Ethiopian Rift Valley [40] and Eritrea [25,42]. The larval density of An. arabiensis increased with increasing habitat temperature and decreasing habitat depth. The occurrence of An. arabiensis larvae in Beko Swamp is an indication of its adaptation to habitats with emergent grass and its expansion to higher elevations, which results in an increased risk of highland malaria. Variability in the $\mathrm{pH}$, turbidity, surface debris and surface algae of the streams did not affect the density of $A n$. arabiensis, An. chrysti, An. cinereus and An. demeilloni larvae significantly. An. arabiensis is adapted to diverse habitats [25,27]. The density of An. chrysti, An. demeilloni and $A n$. cinereus was not significantly correlated with habitat temperature and depth, which indicates that these anophelines can breed at a greater range of depths and temperatures than An. arabiensis. The lower density of the vector (An. arabiensis) in the Beko and Assas habitats of Wurib village may have been due to the relatively low temperature in the area, which may affect its breeding negatively. However, this area supported more of other anopheline species for much of the study period, when compared with the other three permanent breeding habitats. This may be because the grass present in this habitat might have prevented the loss of immature forms in running water or by the direct splashing of rainfall, and the grass might have served as a resting site for newly emerging and gravid anopheline mosquitoes [41].

\section{Conclusion}

This study has revealed that An. arabiensis breeds on the edges and beds of streams in south-central Ethiopia at elevations up to 2200 m.a.s.l. during the dry months. This observation underlines the importance of streams as breeding habitats of An. arabiensis during dry periods. The edges and pools of streams may be important for maintenance of the Anopheles population and for smallscale transmission of malaria during dry seasons. Hence, policy makers and organizations involved in malaria control activities need to consider options for the management of larvae that target streams during dry seasons. This strategy may reduce $A n$. arabiensis density, and thus reduce the risk of malaria transmission [23,32,42]. However, streams might not be the only breeding habitats for anophelines in the area, and hence weekly surveys of all the available habitats and habitat chemistry need to be performed to design a comprehensive and effective larval control strategy. 


\section{Competing interests}

The authors declare that they have no competing interests.

\section{Acknowledgements}

We thank Prof. Getachew Tilahun (ex-director of the Aklilu Lemma Institute of Pathobiology) for his encouragement and facilitating field trips during the surveys. We also thank Nega Nigussie, Yohannes Negash, Wossen Sisay and Zerihun Tesfaye for their technical help both in the field and in the laboratory. Rainfall and temperature data of the Butajira area was obtained from The National Meteorology Agency of Ethiopia. This study was financially supported by NUFU (Project No: NUFUPRO-2007/10121).

\section{Authors' contributions}

AA designed the study, collected data in the field, carried out the data analysis and wrote the first draft of the manuscript. TGM participated in the study design, interpretation of the results and editing of the manuscript. MB participated in the conception of the study, in the study design and editing of the manuscript. BL conceived the idea for the study and took part in the study design, data entry and analysis, data interpretation and editing the manuscript. All authors have read and approved the final manuscript.

Received: 4 November 2011 Accepted: 13 June 2012

Published: 13 June 2012

\section{References}

1. Federal Democratic Ethiopia MoH : National Five-Year Strategic Plan for Malaria Prevention and Control in Ethiopia. Ethiopia: Addis Ababa; 2006.

2. Graves PM, Richards FO, Ngondi J, Emerson PM, Shargie EB, Endeshaw T, Ceccato P, Ejigsemahu Y, Mosher AW, Hailemariam A, Zerihun M, Teferi T, Ayele B, Mesele A, Yohannes G, Tilahun A, Gebre T: Individual, household and environmental risk factors for malaria infection in Amhara, Oromia and SNNP regions of Ethiopia. Trans R Soc Trop Med Hyg 2009, 103: 1211-1220.

3. Yeshiwondim AK, Gopal S, Hailemariam AT, Dengela DO, Patel HP: Spatial analysis of malaria incidence at the village level in areas with unstable transmission in Ethiopia. Int J Health geogr 2009, 8:5.

4. Abeku TA, van Oortmarssen GJ, Borsboom G, de Vlas SJ, Habbema JD: Spatial and temporal variations of malaria epidemic risk in Ethiopia: factors involved and implications. Acta Trop 2003, 87:331-340.

5. White GB, Tessfaye F, Boreham PFL, Lemma G: Malaria vector capacity of Anopheles arabiensis and An. quadriannulatus in Ethiopia: chromosomal interpretation after 6 years storage of field preparations. Trans $R$ Soc Trop Med Hyg 1980, 74:683-684.

6. Krafsur ES, Armstrong JC: An integrated view of entomological and parasitological observations on falciparum malaria in Gambela, Western Ethiopian Lowlands. Trans R Soc Trop Med Hyg 1978, 72:348-356.

7. Balkew M, Elhassen I, Ibrahim M, Gebre-Michael T, Engers H: Very high DDT-resistant population of Anopheles pharoensis Theobald (Diptera: Culicidae) from Gorgora, northern Ethiopia. Parasite 2006, 13:327-329.

8. Fontaine RE, Najjar AE, Prince JS: The 1958 malaria epidemic in Ethiopia. Am J Trop Med Hyg 1961, 10:795-803.

9. Costello A, Abbas M, Allen A, Ball S, Bell S, Bellamy R, Friel S, Groce N, Johnson A, Kett M, Lee M, Levy C, Maslin M, McCoy D, McGuire B, Montgomery H, Papier D, Pagel C, Patel J, Antonio J, de Oliveira P, Redclift N, Rees H, Rogger D, Scott J, Stephenson J, Twigg J, Wolff J, Patterson C: Managing the health effects of climate change: Lancet and University College London Institute for Global Health Commission. Lancet 2009, 373:1693-1733.

10. Kibret $\mathrm{S}$, Alemu $\mathrm{Y}$, Boelee $\mathrm{E}$, Tekie $H$, Alemu D, Petros B: The impact of a small-scale irrigation scheme on malaria transmission in Ziway area, Central Ethiopia. Trop Med Int Health 2010, 15:41-50.

11. Shanks GD, Hay SI, Omumbo JA, Snow RW: Malaria in Kenya's western highlands. Emerg Infec Dis 2005, 11:1425-1432.

12. Ghebreyesus TA, Haile M, Witten KH, Getachew A, Yohannes AM, Yohannes M, Teklehaimanot HD, Lindsay SW, Byass P: Incidence of malaria among children living near dams in northern Ethiopia: community based incidence survey. BMJ 1999, 319:663-666.

13. Minakawa N, Munga S, Atieli F, Mushinzimana E, Zhou G, Githeko AK, Yan G: Spatial distribution of anopheline larval habitats in Western Kenyan highlands: effects of land cover types and topography. Am J Trop Med Hyg 2005, 73:157-165.
14. Bayoh MN, Lindsay SW: Effect of temperature on the development of the aquatic stages of Anopheles gambiae sensu stricto (Diptera: Culicidae). Bull Entomol Res 2003, 93:375-381.

15. Lindsay SW, Martens WJ: Malaria in the African highlands: past, present and future. Bull World Health Organ 1998, 76:33-45.

16. Lindsay SW, Birley MH: Climate change and malaria transmission. Ann Trop Med Parasitol 1996, 90:573-588.

17. Ye Y, Louis VR, Simboro S, Sauerborn R: Effect of meteorological factors on clinical malaria risk among children: an assessment using village-based meteorological stations and community-based parasitological survey. BMC Public Health 2007, 7:101.

18. Pascual M, Ahumada JA, Chaves LF, Rodo X, Bouma M: Malaria resurgence in the East African highlands: temperature trends revisited. Proc Natl Acad Sci U S A 2006, 103:5829-5834.

19. Yewhalaw D, Wassie F, Steurbaut W, Spanoghe P, Van Bortel W, Denis L, Tessema DA, Getachew Y, Coosemans M, Duchateau L, Speybroeck N: Multiple insecticide resistance: an impediment to insecticide-based malaria vector control program. PloS one 2011, 6:e16066.

20. Balkew M, Ibrahim M, Koekemoer LL, Brooke BD, Engers H, Aseffa A, Gebre-Michael T, Elhassen I: Insecticide resistance in Anopheles arabiensis (Diptera: Culicidae) from villages in central, northern and south west Ethiopia and detection of kdr mutation. Parasit Vectors 2010, 3:40.

21. Ketema T, Getahun K, Bacha K: Therapeutic efficacy of chloroquine for treatment of Plasmodium vivax malaria cases in Halaba district. South Ethiopia. Parasit Vectors 2011, 4:46

22. Schunk M, Kumma WP, Miranda IB, Osman ME, Roewer S, Alano A, Loscher T, Bienzle U, Mockenhaupt FP: High prevalence of drug-resistance mutations in Plasmodium falciparum and Plasmodium vivax in southern Ethiopia. Malar J 2006, 5:54.

23. Yohannes M, Haile M, Ghebreyesus TA, Witten KH, Getachew A, Byass P, Lindsay SW: Can source reduction of mosquito larval habitat reduce malaria transmission in Tigray, Ethiopia?. Trop Med Int Health 2005, 10:1274-1285.

24. Omlin FX, Carlson JC, Ogbunugafor CB, Hassanali A: Anopheles gambiae exploits the treehole ecosystem in western Kenya: a new urban malaria risk?. Am J Trop Med Hyg 2007, 77:264-269.

25. Shililu J, Ghebremeskel T, Seulu F, Mengistu S, Fekadu H, Zerom M, Ghebregziabiher A, Sintasath D, Bretas G, Mbogo C, Mbogo C, Githure J, Brantly E, Novak R, Beier JC: Larval habitat diversity and ecology of anopheline larvae in Eritrea. J Med Entomol 2003, 40:921-929.

26. Minakawa N, Sonye G, Yan G: Relationships between occurrence of Anopheles gambiae s.l. (Diptera: Culicidae) and size and stability of larval habitats. J Med Entomol 2005, 42:295-300.

27. Minakawa N, Mutero CM, Githure JI, Beier JC, Yan G: Spatial distribution and habitat characterization of anopheline mosquito larvae in Western Kenya. Am J Trop Med Hyg 1999, 61:1010-1016.

28. Gimnig JE, Ombok M, Kamau L, Hawley WA: Characteristics of larval anopheline (Diptera: Culicidae) habitats in Western Kenya. J Med Entomol 2001, 38:282-288.

29. Gimnig JE, Ombok M, Otieno S, Kaufman MG, Vulule JM, Walker ED: Density-dependent development of Anopheles gambiae (Diptera: Culicidae) larvae in artificial habitats. J Med Entomol 2002, 39:162-172.

30. Deressa W, Ali A, Enqusellassie F: Self-treatment of malaria in rural communities, Butajira, southern Ethiopia. Bull World Health Organ 2003, 81:261-268.

31. Deressa W, Fantahun M, Ali A: Malaria-related mortality based on verbal autopsy in an area of low endemicity in a predominantly rural population in Ethiopia. Malar J 2007, 6:128.

32. Minakawa N, Githure Jl, Beier JC, Yan G: Anopheline mosquito survival strategies during the dry period in western Kenya. J Med Entomol 2001, 38:388-392.

33. Majambere S, Fillinger U, Sayer DR, Green C, Lindsay SW: Spatial distribution of mosquito larvae and the potential for targeted larval control in The Gambia. Am J Trop Med Hyg 2008, 79:19-27.

34. WHO: Manual on practical entomology in malaria. Part II. Methods and Techniques. Division of Malaria and Other Parasitic Diseases Geneva 1975. pp 1-191.

35. WHO: Malaria entomology and vector control: Part 1. Learner's Guide, Trial Edition. HIV/AIDS, Tuberculosis and Malaria, Roll Back Malaria 2003. pp 1-107.

36. Gillies MT, Coetzee M: A supplement to the Anophelinae of Africa south of the Sahara (Afrotropical Region). Publications of the South African Institute for Medical Research 1987, 55:1-143. 
37. Tesfaye S, Belyhun Y, Teklu T, Mengesha T, Petros B: Malaria prevalence pattern observed in the highland fringe of Butajira. Southern Ethiopia: a longitudinal study from parasitological and entomological survey. Malar $J$ 2011, 10:153.

38. Chen H, Githeko AK, Zhou G, Githure Jl, Yan G: New records of Anopheles arabiensis breeding on the Mount Kenya highlands indicate indigenous malaria transmission. Malar J 2006, 5:17.

39. Kweka EJ, Zhou G, Lee MC, Gilbreath TM 3rd, Mosha F, Munga S, Githeko AK, Yan G: Evaluation of two methods of estimating larval habitat productivity in western Kenya highlands. Parasit Vectors 2011, 4:110.

40. Kenea O, Balkew M, Gebre-Michael T: Environmental factors associated with larval habitats of anopheline mosquitoes (Diptera: Culicidae) in irrigation and major drainage areas in the middle course of the Rift Valley, central Ethiopia. J Vector Borne Dis 2011, 48:85-92.

41. Imbahale SS, Paaijmans KP, Mukabana WR, van Lammeren R, Githeko AK, Takken W: A longitudinal study on Anopheles mosquito larval abundance in distinct geographical and environmental settings in western Kenya. Malar J 2011, 10:81.

42. Shililu J, Mbogo C, Ghebremeskel T, Githure J, Novak R: Mosquito larval habitats in a semiarid ecosystem in Eritrea: impact of larval habitat management on Anopheles arabiensis population. Am J Trop Med Hyg 2007, 76:103-110

43. Mutuku FM, Bayoh MN, Gimnig JE, Vulule JM, Kamau L, Walker ED, Kabiru E, Hawley WA: Pupal habitat productivity of Anopheles gambiae complex mosquitoes in a rural village in western Kenya. Am J Trop Med Hyg 2006, 74:54-61.

44. Paaijmans KP, Wandago MO, Githeko AK, Takken W: Unexpected high losses of Anopheles gambiae larvae due to rainfall. PLoS One 2007, 2: e1146.

doi:10.1186/1756-3305-5-117

Cite this article as: Animut et al:: Abundance and dynamics of anopheline larvae in a highland malarious area of south-central Ethiopia. Parasites \& Vectors 2012 5:117.

\section{Submit your next manuscript to BioMed Central and take full advantage of:}

- Convenient online submission

- Thorough peer review

- No space constraints or color figure charges

- Immediate publication on acceptance

- Inclusion in PubMed, CAS, Scopus and Google Scholar

- Research which is freely available for redistribution 